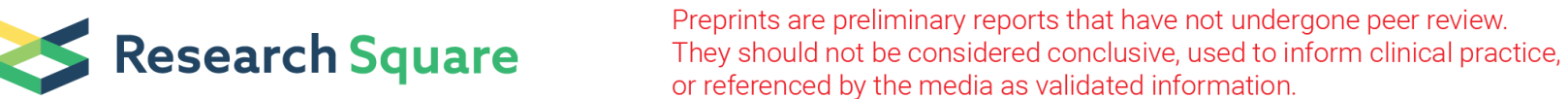

\section{Comparison of Remifentanil Concentrations with and without Dexmedetomidine for the Prevention of Emergence Cough after Nasal Surgery: A Randomized Double Blinded Trial}

Ha Yeon Kim

Ajou University School of Medicine and Graduate School of Medicine https://orcid.org/0000-0003-

3342-4136

Hyun Jeong Kwak

Gachon University Gil Medical Center

Dongchul Lee

Gachon University Gil Medical Center

Ji Hyea Lee

Ajou University School of Medicine and Graduate School of Medicine

Sang Kee Min

Ajou University School of Medicine and Graduate School of Medicine

Jong-Yeop Kim ( $\sim$ kjyeop@ajou.ac.kr)

Ajou University School of Medicine https://orcid.org/0000-0003-3402-365X

Research article

Keywords: cough, dexmedetomidine, emergence, remifentanil

Posted Date: October 8th, 2020

DOI: https://doi.org/10.21203/rs.3.rs-74937/v1

License: (c) (i) This work is licensed under a Creative Commons Attribution 4.0 International License.

Read Full License

Version of Record: A version of this preprint was published at BMC Anesthesiology on May 4th, 2021. See the published version at https://doi.org/10.1186/s12871-021-01358-x. 


\section{Abstract}

Background: After nasal surgery, preventing emergence cough is critical. Emergence cough can provoke immediate postoperative bleeding, which leads to upper airway obstruction. In the present study, we compared the effect-site concentration (Ce) of remifentanil for preventing emergence cough after propofol anesthesia when remifentanil was or was not combined with dexmedetomidine after nasal surgery.

Methods: Forty-seven patients who underwent nasal surgery with propofol-remifentanil anesthesia were randomly divided into a dexmedetomidine group (Group $D, n=23$ ) or a saline group (Group $S, n=24$ ). Group D and Group S were infused dexmedetomidine $(0.5 \mu \mathrm{g} / \mathrm{kg})$ or saline for 10 min before the completion of surgery. Remifentanil was infused a predetermined Ce until extubation. Remifentanil Ce for the prevention of cough in $50 \%$ of patients $\left(\mathrm{EC}_{50}\right)$ and $95 \%$ of patients $\left(\mathrm{EC}_{95}\right)$ was estimated using modified Dixon's up-and-down method and isotonic regression. Hemodynamic and recovery parameters were observed.

Results: The $\mathrm{EC}_{50}$ of remifentanil Ce in Group D was significantly lower than that in Group S $(2.15 \pm 0.40$ $\mathrm{ng} / \mathrm{mL}$ vs. $2.66 \pm 0.36 \mathrm{ng} / \mathrm{mL}, \mathrm{p}=0.023)$. The $\mathrm{EC}_{95}(95 \% \mathrm{Cl})$ of remifentanil Ce was also significantly lower in Group D [2.75 (2.67-2.78) ng/mL] than in Group S [3.16 (3.06-3.18) ng/mL]. Emergence and recovery parameters were comparable between the two groups.

Conclusion: The remifentanil $\mathrm{EC}_{50}$ for the prevention of cough after propofol-remifentanil anesthesia was significantly lower (approximately 19\%) when a combination of remifentanil and $0.5 \mu \mathrm{g} / \mathrm{kg}$ dexmedetomidine was used than when remifentanil infusion alone was used in patients undergoing nasal surgery. Therefore, the Ce of remifentanil may be adjusted for the prevention of emergence cough when used in combination with dexmedetomidine.

Trial registration: ClinicalTrials.gov, NCT03622502, Registered August 9, 2018, https://clinicaltrials.gov

\section{Background}

Emergence cough after general anesthesia leads to serious adverse effects including surgical site bleeding, wound disruption, hemodynamic instability, and increased intracranial and intraocular pressure [1]. The prevention of cough in nasal surgery patients is especially important because cough can provoke immediate postoperative bleeding, which leads to upper airway obstruction [2].

Remifentanil has emerged as a medication for cough prevention after general anesthesia. In prior studies, effective remifentanil effect-site concentrations ( $\mathrm{Ce}$ ) under various conditions have ranged from 1.5 to $2.9 \mu \mathrm{g} / \mathrm{mL}[3-6]$. Although an increasing dose of remifentanil may effectively prevent cough, this drug also increases the incidences of adverse effects including respiratory depression, nausea and vomiting, or delayed emergence $[3,7]$. Thus, to decrease remifentanil's Ce and its side effects when administered alone, co-administration of other adjuvant drugs may prove useful. 
Dexmedetomidine is a highly selective $a_{2}$-agonist and acts as a sedative and analgesic, though it has little effect on respiratory depression even when used at maximum concentrations [8]. A low-dose combination of dexmedetomidine and remifentanil administered prior to surgery is reportedly more effective in preventing emergence cough without respiratory depression than a low-dose of remifentanil alone [9]. In addition, a low-dose combination of dexmedetomidine $(0.5 \mu \mathrm{g} / \mathrm{kg})$ and remifentanil was not inferior to a high dose of remifentanil alone for the prevention of emergence cough [10]. However, the effective remifentanil Ce for the prevention of emergence cough have not been evaluated when administered with a single dose of dexmedetomidine.

The present study was the first to investigate the effective remifentanil $\mathrm{Ce}$ on the prevention of emergence cough after propofol anesthesia in $50 \%$ of patients $\left(\mathrm{EC}_{50}\right)$ and in $95 \%$ of patients $\left(\mathrm{EC}_{95}\right)$ when remifentanil and dexmedetomidine $(0.5 \mu \mathrm{g} / \mathrm{kg})$ were used versus remifentanil alone in patients undergoing nasal surgery.

\section{Methods}

The present prospective trial was done with the approval of the Ajou University Hospital Institutional Review Board (AJIRB-MED-OBS-18-170) and registered at ClinicalTrials.gov (ref no.: NCT03622502). Written informed consent was obtained from all participants. Patients with American Society of Anesthesiologists (ASA) physical status scores of 1 or 2 between the ages of 19 to 65 years who had planned septoplasty or endoscopic sinus surgeries were enrolled. Participant exclusion criteria were a potentially difficult airway (Mallampati class 3 or 4), use of angiotensin converting enzyme-inhibitors, severe obesity (body mass index $>35 \mathrm{~kg} / \mathrm{m}^{2}$ ), current smoker, a recent upper airway infection, asthma, and uncontrolled hypertension. According to a randomization generator (http://www.random.org), patients were randomized into a saline group (Group S) or a dexmedetomidine group (Group D).

After patients entered the operating room (no premedication), anesthetic monitoring including noninvasive blood pressure (BP), electrocardiogram, and pulse oximetry monitoring was applied. To monitor the depth of anesthesia, a bispectral index (BIS) sensor was also applied to the patient's forehead. For anesthesia induction, target-controlled infusion ( $\mathrm{TCl}$ ) was started (propofol Ce of $5.0 \mu \mathrm{g} / \mathrm{mL}$ and remifentanil Ce of $4.0 \mathrm{ng} / \mathrm{mL}$ ) using an infusion device (Orchestra, Fresenius Vial, France). Two min after administration of rocuronium $(0.6 \mathrm{mg} / \mathrm{kg})$, endotracheal intubation was performed using a cuffed tube (inner diameter of $7.5 \mathrm{~mm}$ in males and $7.0 \mathrm{~mm}$ in females) with a cuff pressure of $20-25 \mathrm{mmHg}$.

Anesthesia was maintained with propofol Ce of $2.0-3.0 \mu \mathrm{g} / \mathrm{mL}$ and remifentanil Ce of $3.0-5.0 \mathrm{ng} / \mathrm{mL}$. Anesthetic depth was adjusted from a BIS value of 40 to 60 . Intraoperative heart rate (HR) and BP were adjusted to within $20 \%$ of baseline (before induction of anesthesia). When HR dropped below $45 \mathrm{bpm}$, atropine $(0.5 \mathrm{mg})$ was administered. When mean BP decreased to less than $20 \%$ of baseline mean BP, ephedrine $(6 \mathrm{mg})$ was administered. 
Dexmedetomidine $(0.5 \mu \mathrm{g} / \mathrm{kg})$ in Group D and the same volume of normal saline in Group S were infused over 10 min using a syringe pump before completion of surgery. Upon completion of surgery, propofol infusion was halted. Throughout emergence, remifentanil infusion of predetermined Ce was continued for at least 15 min until extubation. Drugs were administered by one researcher (JY Kim) according to the patient's group identity (dexmedetomidine or normal saline and a pre-determined Ce of remifentanil). Patients' degree of muscle relaxation was assessed using train-of-four (TOF) monitoring. When the TOF ratio was more than $90 \%$, neostigmine $(0.02 \mathrm{mg} / \mathrm{kg})$ and glycopyrrolate $(0.004 \mathrm{mg} / \mathrm{kg})$ were injected. Subsequently, assisted ventilation with $100 \%$ of inspired oxygen was initiated in response to spontaneous patient breathing. When the patient opened their eyes spontaneously or in response to a verbal command, we confirmed that their spontaneous breathing was sufficient and removed their endotracheal tube. Thereafter, remifentanil was stopped and a facial mask delivering $100 \%$ oxygen was applied. The patient was transferred to a post-anesthetic care unit (PACU) after confirming the adequacy of their consciousness and respiration over a 5-min period. In the PACU, the patient was assessed for postoperative nausea and vomiting (PONV). Patient pain was evaluated using a numeric rating scale (NRS), which ranges from 0 (no pain) to 10 (worst possible pain). If the patient suffered from pain rated worse than a 5 or requested painkiller administration, fentanyl $(50 \mu \mathrm{g})$ was injected. Sedation was also evaluated using a modified Wilson sedation scale [11]. When the modified Aldrete score was $\geq 9$, patients were transferred to the ward [12].

Patients were sequentially enrolled using a Dixon's up-and-down allocation approach, as previously [13]. Patient enrolment continued until both groups reached at least 20 patients and six success-failure pairs. Cough was defined as a sudden expulsion of air with abdominal muscle contraction and classified into one of four grades (grade 0: no cough, grade 1: single cough, grade 2: more than one episode of nonsustained cough, grade 3: sustained and repetitive cough). Cough was assessed from the end of surgery to $5 \mathrm{~min}$ after extubation. The Ce of remifentanil was initiated with $2.0 \mathrm{ng} / \mathrm{mL}$ in each group. The next patient's Ce of remifentanil was determined by the previous patient's cough response. If the patient had no cough or a single cough (grade 0 or 1 ), we defined this as successful prevention of cough, and the predetermined Ce of remifentanil for the next patient was lowered by $0.4 \mathrm{ng} / \mathrm{mL}$. If cough was not successfully prevented (grade 2 or 3 ), we determined the result to be a failure at preventing cough, and the pre-determined Ce of remifentanil for the next patient was increased by $0.4 \mathrm{ng} / \mathrm{mL}$.

During the operations, data on the Ce for propofol and remifentanil, mean BP, HR, pulse oximetry saturation $\left(\mathrm{SpO}_{2}\right)$, BIS value, respiratory rate, and end-tidal $\mathrm{CO}_{2}\left(\mathrm{EtCO}_{2}\right)$ were collected at seven time points, namely, baseline (T0), immediately before (T1) and after (T2) the start of dexmedetomidine or saline infusion, upon operation completion (T3), at eye opening (T4), and immediately (T5) and 5 min (T6) after extubation. In addition, the intraoperative use of medications to control BP or HR was recorded.

Cough was assessed by one researcher (HY Kim), from whom patients' group allocations and the predetermined Ce of remifentanil was concealed. The times elapsed between stopping propofol administration to eye opening (time to eye opening) and from stopping propofol administration to extubation (time to extubation) were recorded. For 5 min after extubation, bradypnea (respiratory rate $<8$ 
breaths/min), laryngospasm, and desaturation $\left(\mathrm{SpO}_{2}<95 \%\right)$ were recorded. In the PACU, respiratory rate, PONV, pain scores using the NRS, Aldrete score, sedation scale, and stay duration were recorded.

\section{Statistical analyses}

The $\mathrm{EC}_{50}$ and $\mathrm{EC}_{95}$ of remifentanil for preventing cough in Group $\mathrm{D}$ were the primary study outcomes. To obtain the $\mathrm{EC}_{50}$ by Dixon's up-and-down method, at least six success-failure pairs and 20 patients were needed [14]. The $\mathrm{EC}_{50}$ of remifentanil was defined as the mean value of the mid-point for each failure-tosuccess pair. To obtain the $\mathrm{EC}_{95}$ of remifentanil, the isotonic regression method using a pooled-adjacentviolators algorithm and a bootstrapping approach was also used, as previously [15]. No overlap between two $\mathrm{EC}_{95}$ values at $95 \%$ confidence interval $(\mathrm{Cl})$ was considered a significant difference [16].

Categorical variables were analyzed using the chi-squared or Fisher's exact tests, and continuous variables were analyzed using independent t-tests or Mann-Whitney $U$ tests. Measured variables were repeatedly analyzed using the linear mixed model (LMM). When the model revealed a significant interaction between group and time, a post-hoc analysis was performed to identify time points which differed significantly. Data are shown as means \pm standard deviations (SDs), medians (interquartile range, IQR), or numbers (frequency). A P-value less than 0.05 was considered significant. Statistics were analyzed with SPSS (version 25.0, IBM Corporation, Armonk, NY, USA) and R (version 3.2.5)

\section{Results}

Forty-eight patients were enrolled between August 2018 and March 2019. One patient was withdrawn due to incorrect initiation of dexmedetomidine, leaving 23 patients in Group D and 24 patients in Group S who completed the study (Fig. 1). Preoperative patient characteristics and intraoperative details were comparable between the two groups (Table 1). 
Table 1

Preoperative and intraoperative patient characteristics.

\begin{tabular}{|llll|}
\hline & Group D ( $\mathbf{n = 2 3 )}$ & Group S $(\mathbf{n = 2 4 )}$ & P-value \\
\hline Sex, male n (\%) & $14(61)$ & $19(79)$ & 0.636 \\
\hline Age, years & $40 \pm 12$ & $40 \pm 14$ & 0.875 \\
\hline Weight, kg & $74(66-84)$ & $73(64-76)$ & 0.442 \\
\hline Height, cm & $170(160-176)$ & $172(166-182)$ & 0.248 \\
\hline ASA classification (I/II), $\mathrm{n}$ & $19 / 4$ & $18 / 6$ & 0.724 \\
\hline Operation time, min & $35(25-40)$ & $30(25-44)$ & 0.765 \\
\hline Anesthesia time, min & $70(60-75)$ & $70(60-89)$ & 0.579 \\
\hline Values are mean \pm SD, median (25th - 75th IQR), or number (\%). & \\
\hline ASA, American Society of anesthesiologist & & \\
\hline
\end{tabular}

Successes and failures to prevent emergence cough in consecutive patients are shown in Fig. 2. $\mathrm{EC}_{50} \mathrm{~S}$ were calculated by Dixon's method from eight failure-success pairs in Group D and from seven failuresuccess pairs in Group S. The $\mathrm{EC}_{50}$ for remifentanil was significantly lower in Group D than in Group S ( $2.15 \pm 0.04$ vs. $2.66 \pm 0.36 \mathrm{ng} / \mathrm{mL}$, respectively, $\mathrm{P}=0.023)$. The $\mathrm{EC}_{95}(95 \% \mathrm{Cl})$ for remifentanil was also significantly lower in Group D than in Group S [2.75 (2.67-2.78) vs. $3.16(3.06-3.18) \mathrm{ng} / \mathrm{mL}$, respectively], and their $95 \%$ Cls did not overlap.

During surgery, repeated measure variables including $\mathrm{MBP}, \mathrm{HR}, \mathrm{SpO}_{2}, \mathrm{BIS}$ value, and $\mathrm{EtCO}_{2}$ had similar trends over time in both groups (all p values $>0.05$ ) (data not shown). The number of patients who were administered ephedrine did not differ between the two groups [9 (39.1\%) in Group D vs. $11(45.8 \%)$ in Group $S, p=0.642]$. One patient in Group D received atropine.

During emergence, time to eye opening, time to extubation, and respiration rate did not differ between the two groups. Bradypnea within 5 min of extubation occurred in six patients in Group D and in nine patients in Group $S(P=0.401)$. This bradypnea was transient in all patients and recovered with respiratory encouragement (Table 2). 
Table 2

Emergence and recovery parameters.

\begin{tabular}{|c|c|c|c|}
\hline & Group D $(n=23)$ & Group S $(n=24)$ & $P$-value \\
\hline \multicolumn{4}{|l|}{ During emergence } \\
\hline Time to eye opening, sec & $560(490-670)$ & $565(453-714)$ & 0.975 \\
\hline Time to extubation, sec & $670(630-750)$ & $690(540-795)$ & 0.775 \\
\hline \multicolumn{4}{|l|}{ Respiration rate, breaths/min } \\
\hline Immediately after extubation & $10(9-12)$ & $12(9-13)$ & 0.412 \\
\hline 5 min after extubation & $12(12-13)$ & $12(10-13)$ & 0.360 \\
\hline Bradypnea, n (\%) & $6(26)$ & $9(38)$ & 0.401 \\
\hline \multicolumn{4}{|l|}{ In the post-anesthesia care unit } \\
\hline Pain score, NRS & $2(2-3)$ & $2(2-3)$ & 0.644 \\
\hline Rescue analgesics, n (\%) & $2(10)$ & $2(9)$ & 0.456 \\
\hline PONV, n (\%) & $4(18)$ & $2(9)$ & 0.414 \\
\hline Duration of stay, min & $30(30-40)$ & $30(30-40)$ & 0.745 \\
\hline \multicolumn{4}{|c|}{ Values are median (25th - 75th IQR), or number (\%). } \\
\hline \multicolumn{4}{|c|}{ NRS, numeric rating scale $(0=$ none, $10=$ the worst): PONV postoperative nausea and vomiting } \\
\hline
\end{tabular}

In the PACU, postoperative pain scores, the number of patients receiving rescue analgesics, PONV, and duration of stay did not differ between the two groups. Respiratory rate, Aldrete scores, and sedation scale scores also did not interact significantly with time and group (data not shown).

\section{Discussion}

In the present study, we evaluated remifentanil's Ce for the prevention of emergence cough after propofol anesthesia administration with and without co-administration of dexmedetomidine $(0.5 \mu \mathrm{g} / \mathrm{kg})$. The combined infusion of dexmedetomidine and remifentanil significantly reduced remifentanil $\mathrm{EC}_{50}$ and $\mathrm{EC}_{95}$ measures by $19 \%$ and $13 \%$, respectively, compared to remifentanil infusion alone. In addition, the combined use of these drugs did not delay the time to awakening or extubation and did not aggravate respiratory depression.

Cough is mediated by peripheral nerve terminals within the airway walls and by central vagus afferent nerves in the nodose ganglia or bodies of the jugular $[17,18]$. Several antitussive agents are known to inhibit peripheral cough pathways (e.g. local anesthetics), central cough pathways (e.g. gammaaminobutyric acid agonists), or both cough pathways (e.g. opioids) $[17,18]$. Of these, remifentanil is the antitussive agent of choice for use during anesthesia due to its uniquely rapid action without 
accumulation [7]. However, although remifentanil has a dose-dependent antitussive effect, it also has dose-dependent adverse effects such as respiratory depression, muscle rigidity, nausea and vomiting, pruritus, or delayed emergence [3, 7].

In recent years, the application of dexmedetomidine as a sedative and analgesic which does not cause respiratory depression has grown [19]. Given this, several studies have assessed the efficacy of dexmedetomidine for the prevention of cough [20-24]. At present, there have been conflicting results regarding the antitussive effects of dexmedetomidine. Several studies have reported that dexmedetomidine may not prevent cough better than remifentanil, midazolam, or even saline [20-22]. However, other studies have reported that dexmedetomidine may prevent cough better than placebo (saline) $[23,24]$ and that it may have dose-dependent antitussive effects [23]. Although the efficacy of dexmedetomidine as an antitussive agent has not been fully evaluated, dexmedetomidine combined with remifentanil may be more effective at preventing cough than remifentanil alone $[9,10]$. However, studies have reported that the combined use of dexmedetomidine and remifentanil to prevent cough during emergence lead to delayed emergence compared to the use of remifentanil alone $[9,10]$. Therefore, clarifying what dose of remifentanil should be used in combination with dexmedetomidine to prevent cough during emergence remains necessary.

The present study revealed differences of $0.4-0.5 \mathrm{ng} / \mathrm{mL}$ between the remifentanil $\mathrm{EC}_{50}$ and $\mathrm{EC}_{95}$ between the two groups. In addition, a reduced $\mathrm{Ce}$ of remifentanil when dexmedetomidine was combined did not delay emergence time (from eye opening to extubation) compared to the use of remifentanil alone. In the present study, the remifentanil $\mathrm{EC}_{95}$ after nasal surgery when remifentanil was used alone was $3.16 \mathrm{ng} / \mathrm{mL}$. This remifentanil Ce was a substantially higher dose than that reported previously in the context of thyroid surgery $(2.14 \mathrm{ng} / \mathrm{mL})$ or brain tumour surgery $(2.51 \mathrm{ng} / \mathrm{mL})[25,26]$. Meanwhile, Choi et al. [4] found that the ideal remifentanil $\mathrm{EC}_{95}$ for preventing cough after nasal surgery was $2.94 \mathrm{ng} / \mathrm{mL}$, comparable to that reported here. Choi et al. suggested that coughing was more frequent after nasal surgery than other type of surgery, potentially because of chronic inflammation in the nasal mucosa, perioperative mechanical irritation, and pharyngolaryngeal stimulation by blood. Thus, the type of surgery could be one factor which determines the ideal remifentanil Ce for preventing emergence cough.

Despite our findings, the use of high concentrations of remifentanil (e.g., above $3.0 \mathrm{ng} / \mathrm{mL}$ ) for the prevention of cough may not be practical given that remifentanil infusion during emergence under propofol anesthesia may increase the hypnotic effects of propofol and respiratory depression [27]. In a previous study, remifentanil infusion at $3.0 \mathrm{ng} / \mathrm{mL}$ during laryngomicroscopic surgery after propofol anesthesia led to a higher incidence of hypoventilation and longer extubation time during emergence than remifentanil infusion at $2.6 \mathrm{ng} / \mathrm{mL}$ or less [6]. This result indicates that the combined use of dexmedetomidine and remifentanil for preventing emergence cough is feasible in clinical settings.

In the present study, the combined use of remifentanil and dexmedetomidine did not attenuate hemodynamic changes during extubation better than remifentanil alone. This is in contrast to previous reports in which hemodynamic changes were attenuated better with combined dexmedetomidine 
$(0.5 \mu \mathrm{g} / \mathrm{mL})$ and remifentanil $(1 \mathrm{ng} / \mathrm{mL})$ than with remifentanil infusion alone [9]. The mean Ces for remifentanil in the present study were 2.1 in Group $D$ and $2.5 \mathrm{ng} / \mathrm{mL}$ in Group S. Remifentanil attenuated hemodynamic changes during emergence in a dose-dependent manner [5]. Thus, relatively high doses of remifentanil may have offset the cardiovascular effects of dexmedetomidine. Meanwhile, recovery profiles including respiratory rate were not different between the two groups, paralleling findings from a previous study by Kim et al. [10]. Kim et al. [10] suggested that remifentanil plays a major role in regulating respiratory profiles when combined with dexmedetomidine because it does not worse the respiratory depression caused by remifentanil.

The present study has several limitations. First, although the Dixon' up-and-down method allows for good median estimation, it is a simple strategy. Because such median estimations depend on the chosen pairs (e.g. success-failure pairs or failure-success pairs) and clinical circumstances, the $\mathrm{EC}_{50}$ is a relative and not absolute value. Second, this study's sample size was determined using the Dixon' up-and-down allocation approach and may therefore be insufficient to confirm differences in secondary outcomes between the two groups. Third, all cases included in this study were performed under propofol anesthesia. Therefore, different results may emerge in cases which utilize inhalational anesthesia.

\section{Conclusions}

The Ce for remifentanil for the prevention of emergence cough after propofol anesthesia administration was significantly lower when a single dose of dexmedetomidine $(0.5 \mu \mathrm{g} / \mathrm{kg})$ was co-infused with remifentanil than when remifentanil was administered alone in nasal surgery patients.

\section{Abbreviations}

ASA: American Society of Anesthesiologists; BIS: bispectral index; BP: blood pressure; Ce: effect-site concentration; $\mathrm{Cl}$ : confidence interval; $\mathrm{EC}_{50}$ : effective concentration in $50 \%$ of patients; $\mathrm{EC}_{95}$ : effective concentration in $95 \%$ of patients; $\mathrm{ETCO}_{2}$ : end-tidal $\mathrm{CO} 2 ; \mathrm{HR}$ : heart rate; IQR: interquartile range; LMM: linear mixed model; NRS: numeric rating scale; PACU: post-anesthetic care unit; PONV: postoperative nausea and vomiting; $\mathrm{SD}$ : standard deviations; $\mathrm{SPO}_{2}$ : pulse oximetry saturation; $\mathrm{TCl}$ : target-controlled infusion; TOF: train-of-four

\section{Declarations}

\section{Ethics approval and consent to participate}

This study was approved by the Ethics Committee of the Ajou University Hospital Institutional Review Board (AJIRB-MED-OBS-18-170). Written informed consent was obtained from all subjects participating in the trial. The trial was registered prior to patient enrollment at ClinicalTrials.gov (ref no.:

NCT03622502). 


\section{Consent for publication}

All data published here are under the consent for publication. Written informed consent was obtained from all individual participants included in the study.

\section{Availability of data and materials}

The datasets generated and analyzed during the present study are available from the corresponding author on reasonable request.

\section{Competing interests}

The authors declare that they have no conflict of interest.

\section{Funding}

Not applicable.

\section{Authors' contributions}

HYK: data collection, manuscript drafting and editing. HJK: study design, and interpretation. DL: formal analysis. JHL: data collection and analysis. SKM: supervision. JYK: study design, manuscript drafting and editing. All of the authors have read and approved the manuscript.

\section{Acknowledgements}

Not Applicable.

\section{References}

1. Irwin RS. Complications of cough: ACCP evidence-based clinical practice guidelines. Chest. 2006;129:54s-8s.

2. Halderman AA, Sindwani R, Woodard TD. Hemorrhagic Complications of Endoscopic Sinus Surgery. Otolaryngol Clin North Am. 2015;48:783-93.

3. Chang CH, Lee JW, Choi JR, Shim YH. Effect-site concentration of remifentanil to prevent cough after laryngomicrosurgery. Laryngoscope. 2013;123:3105-9.

4. Choi EM, Park WK, Choi SH, Soh S, Lee JR. Smooth emergence in men undergoing nasal surgery: the effect site concentration of remifentanil for preventing cough after sevoflurane-balanced 
anaesthesia. Acta Anaesthesiol Scand. 2012;56:498-503.

5. Jun NH, Lee JW, Song JW, Koh JC, Park WS, Shim YH. Optimal effect-site concentration of remifentanil for preventing cough during emergence from sevoflurane-remifentanil anaesthesia. Anaesthesia. 2010;65:930-5.

6. Kim HY, Kim JY, Ahn SH, Lee SY, Park HY, Kwak HJ. Predicting effective remifentanil concentration in $95 \%$ of patients to prevent emergence cough after laryngomicroscopic surgery. Medicine (Baltimore). 2018;97:e11258.

7. Servin FS, Billard V. Remifentanil and other opioids. Handb Exp Pharmacol. 2008; doi:10.1007/978-3540-74806-9_14:283-311.

8. Hsu YW, Cortinez LI, Robertson KM, Keifer JC, Sum-Ping ST, Moretti EW, et al. Dexmedetomidine pharmacodynamics: part l: crossover comparison of the respiratory effects of dexmedetomidine and remifentanil in healthy volunteers. Anesthesiology. 2004;101:1066-76.

9. Lee JS, Choi SH, Kang YR, Kim Y, Shim YH. Efficacy of a single dose of dexmedetomidine for cough suppression during anesthetic emergence: a randomized controlled trial. Can $\mathrm{J}$ Anaesth. 2015;62:392-8.

10. Kim JH, Ham SY, Kim DH, Chang CH, Lee JS. Efficacy of Single-Dose Dexmedetomidine Combined with Low-Dose Remifentanil Infusion for Cough Suppression Compared to High-Dose Remifentanil Infusion: A Randomized, Controlled, Non-Inferiority Trial. Int J Med Sci. 2019;16:376-83.

11. Nemethy M, Paroli L, Williams-Russo PG, Blanck TJ. Assessing sedation with regional anesthesia: inter-rater agreement on a modified Wilson sedation scale. Anesth Analg. 2002;94:723-8; table of contents.

12. Aldrete JA. The post-anesthesia recovery score revisited. J Clin Anesth. 1995;7:89-91.

13. Dixon WJ. Staircase bioassay: the up-and-down method. Neurosci Biobehav Rev. 1991;15:47-50.

14. Pace NL, Stylianou MP. Advances in and limitations of up-and-down methodology: a precis of clinical use, study design, and dose estimation in anesthesia research. Anesthesiology. 2007;107:144-52.

15. Dilleen M, Heimann G, Hirsch I. Non-parametric estimators of a monotonic dose-response curve and bootstrap confidence intervals. Stat Med. 2003;22:869-82.

16. Payton ME, Greenstone MH, Schenker N. Overlapping confidence intervals or standard error intervals: what do they mean in terms of statistical significance? J Insect Sci. 2003;3:34.

17. Canning BJ, Chang AB, Bolser DC, Smith JA, Mazzone SB, McGarvey L. Anatomy and neurophysiology of cough: CHEST Guideline and Expert Panel report. Chest. 2014;146:1633-48.

18. Spina D, McFadzean I, Bertram FK, Page CP. Peripheral mechanisms II: the pharmacology of peripherally active antitussive drugs. Handb Exp Pharmacol. 2009; doi:10.1007/978-3-540-798422_8:155-86.

19. Weerink MAS, Struys M, Hannivoort LN, Barends CRM, Absalom AR, Colin P. Clinical Pharmacokinetics and Pharmacodynamics of Dexmedetomidine. Clin Pharmacokinet. 2017;56:893913. 
20. Ryu JH, Lee SW, Lee JH, Lee EH, Do SH, Kim CS. Randomized double-blind study of remifentanil and dexmedetomidine for flexible bronchoscopy. Br J Anaesth. 2012;108:503-11.

21. Gao Y, Kang K, Liu H, Jia L, Tang R, Zhang X, et al. Effect of dexmedetomidine and midazolam for flexible fiberoptic bronchoscopy in intensive care unit patients: A retrospective study. Medicine. 2017;96:e7090-e.

22. Kim SY, Kim JM, Lee JH, Song BM, Koo BN. Efficacy of intraoperative dexmedetomidine infusion on emergence agitation and quality of recovery after nasal surgery. Br J Anaesth. 2013;111:222-8.

23. Aouad MT, Zeeni C, Al Nawwar R, Siddik-Sayyid SM, Barakat HB, Elias S, et al. Dexmedetomidine for Improved Quality of Emergence From General Anesthesia: A Dose-Finding Study. Anesth Analg. 2019;129:1504-11.

24. Guler G, Akin A, Tosun Z, Eskitascoglu E, Mizrak A, Boyaci A. Single-dose dexmedetomidine attenuates airway and circulatory reflexes during extubation. Acta Anaesthesiol Scand. 2005;49:1088-91.

25. Choi SH, Min KT, Lee JR, Choi KW, Han KH, Kim EH, et al. Determination of EC95 of remifentanil for smooth emergence from propofol anesthesia in patients undergoing transsphenoidal surgery. $J$ Neurosurg Anesthesiol. 2015;27:160-6.

26. Lee B, Lee JR, Na S. Targeting smooth emergence: the effect site concentration of remifentanil for preventing cough during emergence during propofol-remifentanil anaesthesia for thyroid surgery. $\mathrm{Br}$ J Anaesth. 2009;102:775-8.

27. Bouillon TW, Bruhn J, Radulescu L, Andresen C, Shafer TJ, Cohane C, et al. Pharmacodynamic interaction between propofol and remifentanil regarding hypnosis, tolerance of laryngoscopy, bispectral index, and electroencephalographic approximate entropy. Anesthesiology. 2004;100:135372.

\section{Figures}




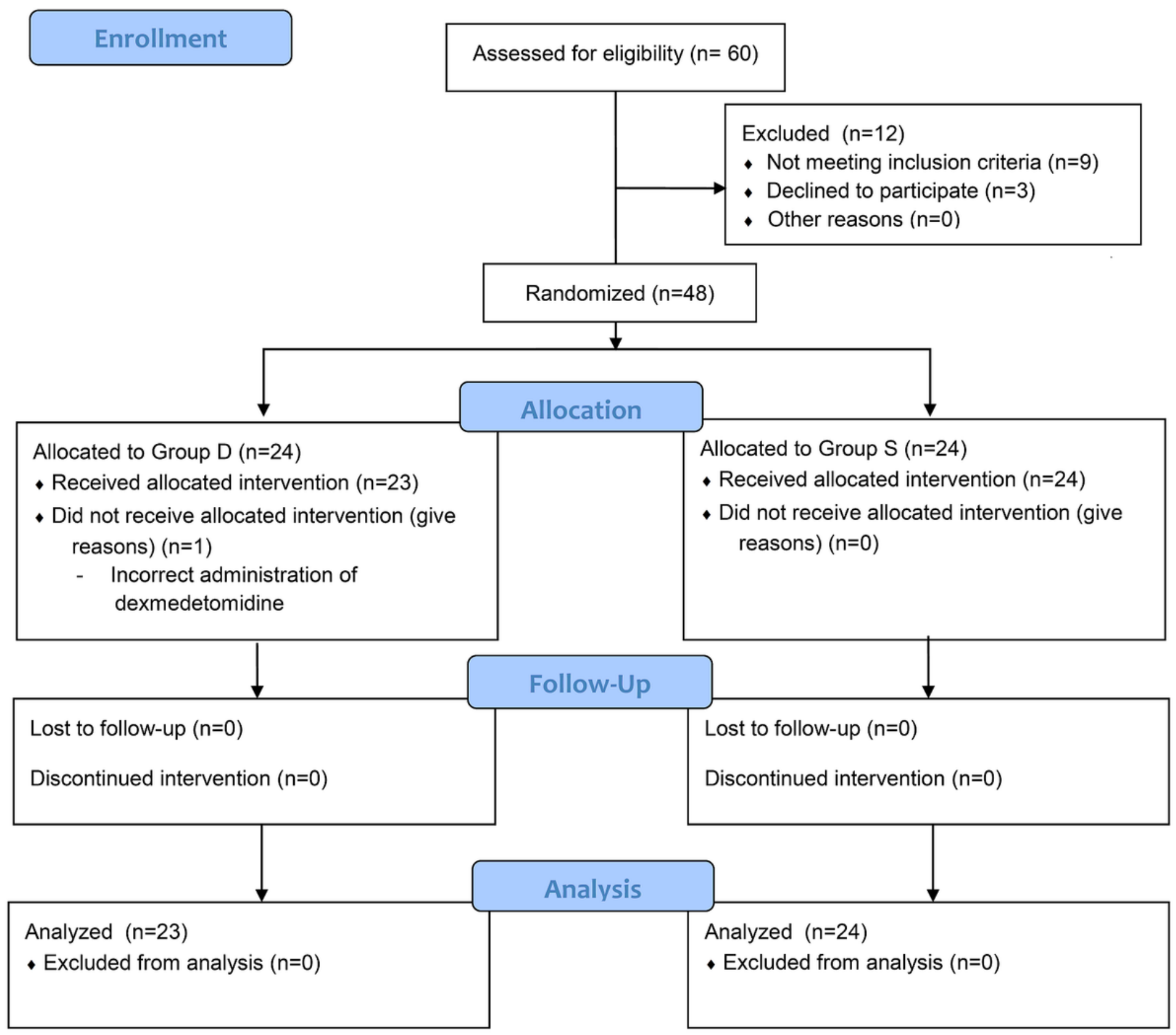

\section{Figure 1}

The CONSORT flow diagram 
A.

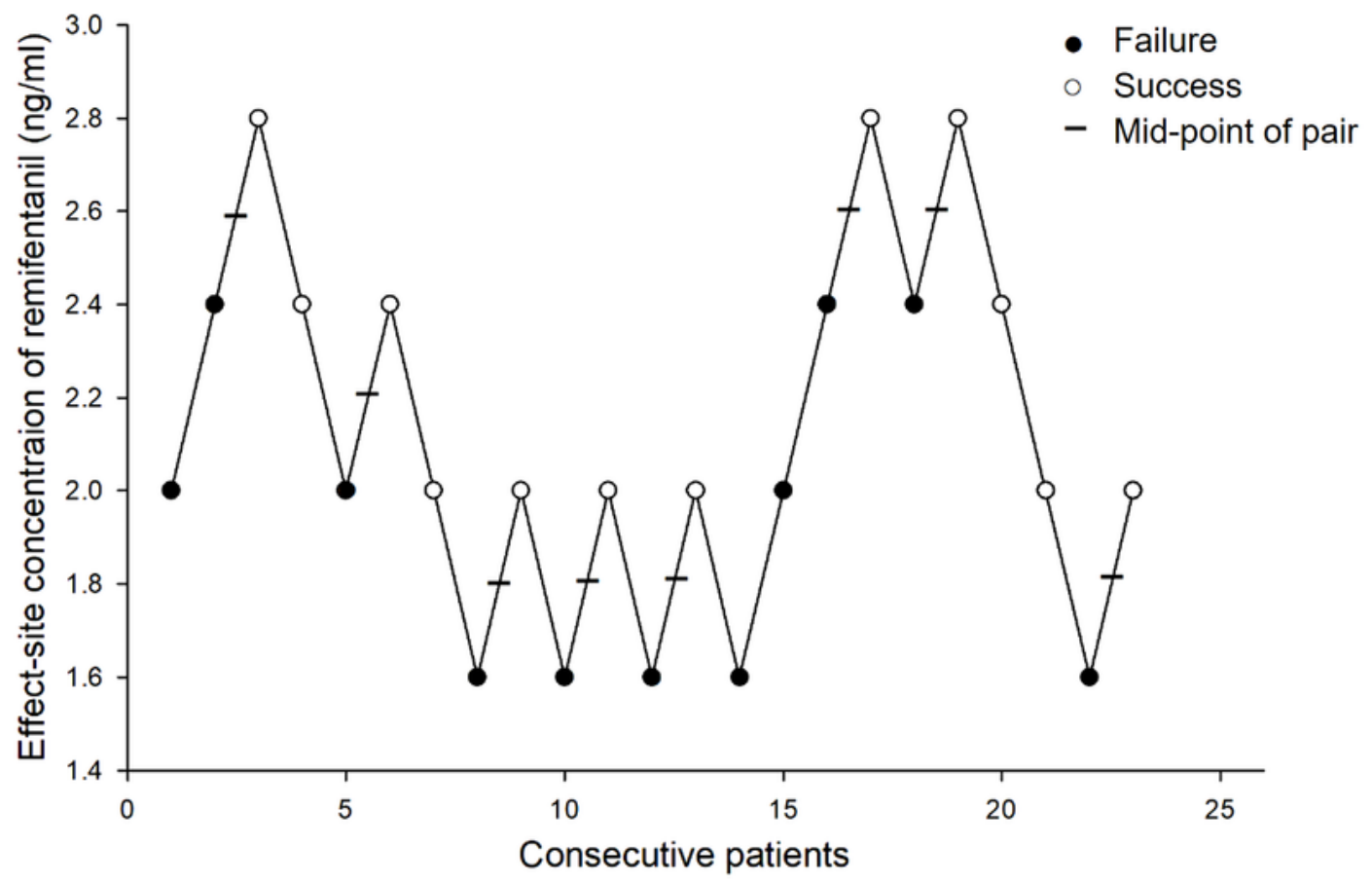

B.

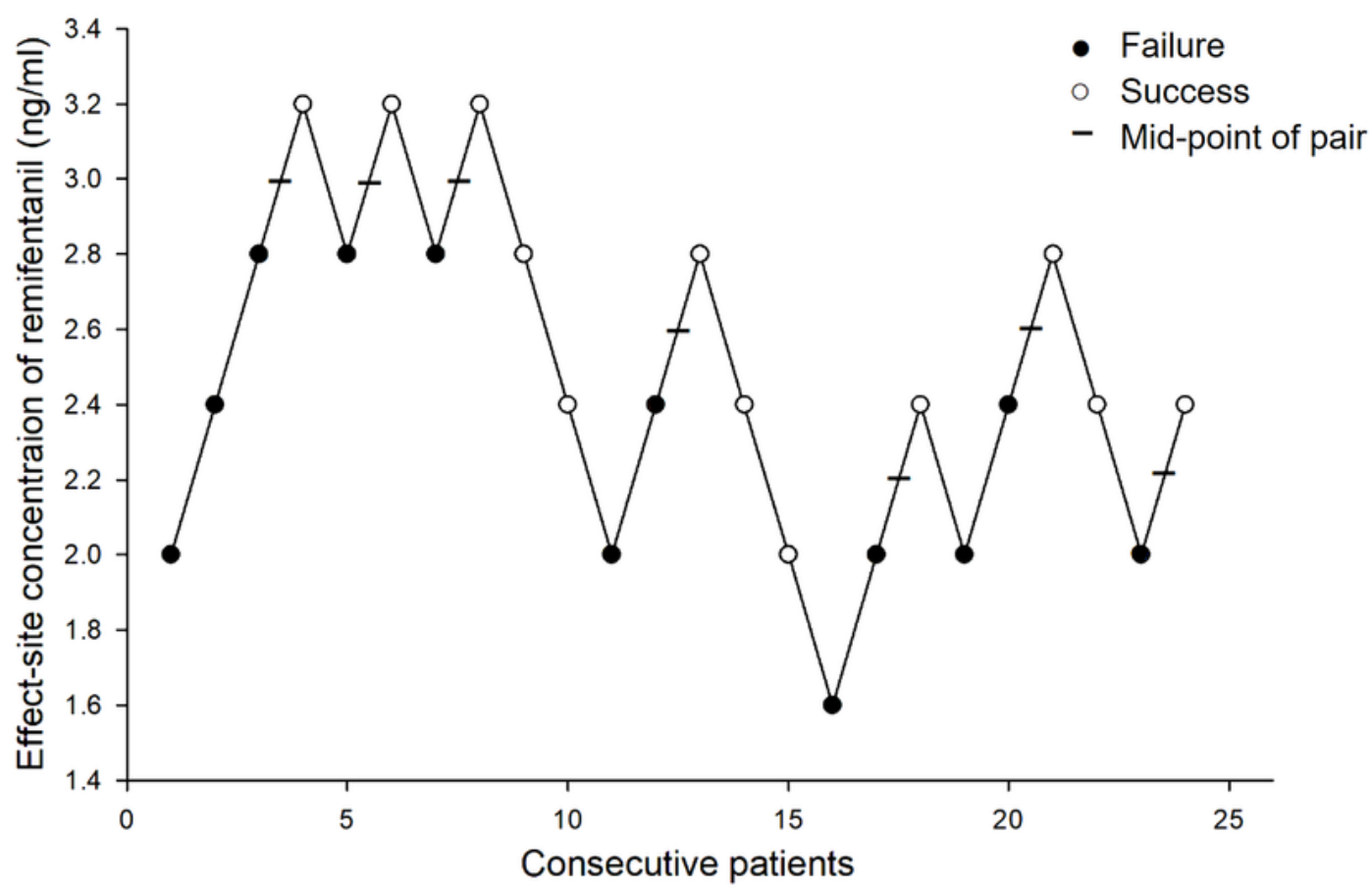

Figure 2

Effect-site concentration of remifentanil by Dixon's methods in Group $D(A)$ and in Group $S(B)$

\section{Supplementary Files}

This is a list of supplementary files associated with this preprint. Click to download. 
- CONSORTchecklist.doc

Page 15/15 